\author{
ANNEKE SMELIK AND LIANNE TOUSSAINT \\ Radboud University Nijmegen, the Netherlands \\ PAULINE VAN DONGEN \\ Technical University Eindhoven, the Netherlands
}

\title{
Solar fashion: An embodied approach to wearable technology
}

\begin{abstract}
Using Pauline van Dongen's 'Wearable Solar' project as a case study, the authors argue that materiality and embodiment should be taken into account both in the design of and the theoretical reflection on wearable technology. Bringing together a fashion designer and scholars from cultural studies, this interdisciplinary research aims at advancing the design and academic study of wearable technology. The interdisciplinary framework involves a mixed-method approach: a combination of research through design; interviews with wearers during fittings; and theoretical reflection. A theoretical and methodological focus on materiality allows for a sustained analysis of embodiment and embodied experience, while it also enables attention to the materiality of the textile and the technology involved. This 'embodied approach' is situated in 'new materialism' and more specifically in a reappraisal of Merleau-Ponty's phenomenology. Through the exploration of 'embodied design', the lived experience of the wearer is incorporated into design practice, research methods and theoretical analysis. The relevance of wearable technology for potential future users can only be advanced when new meanings and values are created through interaction with the design. Working through a phenomenologically driven research through design, solar technology is better integrated into fashion so as to make 'solar fashion' more wearable in the near future.
\end{abstract}

\section{KEYWORDS}

wearable technology wearable solar solar energy new materialism phenomenology embodied design 
We eat light, drink it in through our skins. With a little more exposure to light, you feel part of things physically. I like feeling the power of light and space physically because then you can order it materially.

Artist James Turrell (cited in Cadena 2010: 357)

\section{POWERED BY THE SUN}

When Pauline van Dongen wore her self-designed 'Solar Shirt' during the festival 'South by Southwest' in 2015 in Austin (Texas), she observed how the shirt made her more aware of her surroundings. In the grid-planned city she started walking on the sides of the street bathed in sunlight in order to generate more energy with the solar cells embedded in the textile. The shirt did not remain unnoticed. Random passers-by commented on the look of the shirt or asked in surprise: 'Are those solar cells?' The rather unusual material and aesthetics of the shirt clearly stood out. This example shows the potential for embedding technology into fashion design as well as the importance of designing for the embodied, contextual and social experience of wearing technology on the body.

This article presents some of the preliminary results of our joint research on wearable technology, focusing on the integration of solar technology, also known as photovoltaic (PV) cells, into fashion. Combining design practice with qualitative research and theoretical reflection, we propose an embodied research approach to wearable technology that acknowledges the material, physical and social features of this particular field of 'solar fashion'. With the term wearable technology, or simply wearables, we refer to the integration of technology into fibres, textiles or garments. An alternative term is 'fashionable technology', introduced by Sabine Seymour $(2009,2010)$ to bring the field of wearable computation more closely to the field of fashion. We use these two terms interchangeably in this article.

Historically, the field of textiles and dress is closely knitted to technology: as Bradley Quinn writes, '[t]echnology has always been the essence of fashion' (2002: 14). However, Susan E. Ryan argues that the connections between fashion and technology have become stronger and more ideological in the modern period (2014: 6). Having its roots in the wearable computation of the late 1980s and 1990s, the field of fashionable or wearable technology has become broader and more diverse over the past few decades; Quinn (2002, 2012) supplies good overviews of its historical development, as does Ryan (2014). Wearable technology is often situated within a discourse of futurism, but to date, as Ryan (2014) quite rightly observes, most books tend to give overviews of technological developments without much interpretation or critical engagement (e.g. Braddock and O'Mahony 1999, 2005; Quinn 2002, 2012; Seymour 2009, 2010). In this article we intend to redress this omission.

In order to understand and evaluate the changes and transformations that are involved in fashion design for wearable technology, and in the design of solar fashion particularly, we propose an 'embodied' approach (Dourish 2004; Tomico and Wilde 2015). By 'embodied' approach we mean a theoretical attention to and methodological analysis of the role of the body in the designing process; the experience of the wearer; and the materiality of the textiles and technologies. The proposed focus on materiality and embodiment can be situated in what has been called 'new materialism(s)' (Barrett and Bolt 2012; Coole and Frost 2010). The theoretical framework for our research thus builds on the recent 'materialist turn' (Bennett and Joyce 2010). From the many 
strands that inform new materialism (e.g. Marxism, Deleuzean philosophy, feminism; see Rocamora and Smelik, 2016), we choose to focus on phenomenology as developed by Maurice Merleau-Ponty. Embodied experience and the perceiving body are key topics in phenomenological theory. They are of particular relevance to our theoretical and methodological approach because wearing technology, by definition, involves bodily sensations. Phenomenology provides some of the conceptual tools to address the ways in which wearable technology in general, and solar fashion in particular, affects the wearer's embodied experience.

By presenting the first results of our interdisciplinary research project 'Crafting Wearables'1, we aim to advance the design and scholarly study of wearable technology. The interdisciplinary framework allows for a mixedmethod approach: a combination of research through design (Koskinen et al. 2011); interviews with wearers during fittings; and theoretical reflection. Bringing a fashion designer, technicians, scientists and scholars together, 'Crafting Wearables' explores how technology influences the design process, and vice versa. Within the project, fashion designer Pauline van Dongen performs 'Research through Design' (Frayling 1993); combining material research with development work and practical experiments (Löwgren 2013), she researches different kinds of technology, such as solar technology, 3D printing and LED lights through the practice of fashion design.

For this article we focus specifically on the possible applications of solar energy for fashion. On the one hand, there is an environmental and economic global urgency to change from fossil fuels to renewable energy, causing diverse applications for solar energy to flourish: from the booming rooftop solar industry to mobile applications in bags or backpacks and, more recently, the integration of flexible solar cells into textiles and garments. On the other hand, designers and researchers from the field of wearable technology are increasingly looking for ways to creatively solve the energy-supply problem of wearables (for a discussion of this problem, see Min 2009). The use of solar panels for dress and fashion combines both quests, allowing the wearer to save up and use solar energy; for example, for loading up a mobile phone while also solving the issue of power supply. The development of solar fashion or solar textiles (Wilson and Mather 2015) has previously been explored in designs such as Diffus's solar-powered handbag 'Eclipse' (2011) and Zegna Sport's 'Ecotech Solar Jacket' (2009). Both designs incorporated rigid crystalline solar cells rather than the flexible thin-film solar cells used in the two designs discussed in this article.

Fashionable technology can thus advance sustainability, which is not exactly a luxury considering the rather dire state of affairs in the field of fashion production and consumption. Combining two of the hottest topics in the world of fashion today - sustainability and technology - solar fashion seems to hold a promising future. Yet although the potential is clearly there, the integration of solar technology into fashion is a particularly 'tough shell' (Stinson 2014). Requiring a balanced combination of technical functionality, wearability and aesthetic appeal, fashionable technologies confront fashion designers and researchers with many challenges and questions.

Our main research question is how to better design and understand the material and embodied properties of wearable technology, in this case solar fashion. Using Pauline van Dongen's 'Wearable Solar' project as a case study, we argue that the two key factors of materiality and embodiment should be taken into account both in the design and in the theoretical reflection on
1. The interdisciplinary research project 'Crafting Wearables' (2013-18) consists of a cooperation between the Radboud University Nijmegen, the Technical University Eindhoven and the ArtEZ Academy of Fashion in Arnhem. It is funded by the Netherlands Organization for Scientific Research and supported by several private partners such as Philips Research and the Textile Museum in Tilburg. The project aims to close the existing gaps between the different fields of fashion, technology, industry and academic scholarship in order to understand how wearables can be made more successful. See: www. craftingwearables.com 
2. See for example: http:// goo.gl/7PtıBl; http:// goo.gl/suFRuK; http:// goo.gl/gzopoL; and http://goo.gl/QDAgOu All accessed 5 February 2015 wearable technology. We first discuss the design process of the 'Wearable Solar Dress' (2013) and then analyse the design from a phenomenological perspective. In the last part of the article we advance our argument by discussing the 'Solar Shirt' (2015), and conclude by wrapping up the interplay between practice and theory.

\section{'WEARABLE SOLAR DRESS'}

When Pauline van Dongen first presented her 'Solar Dress' in 2013 it was immediately picked up by the media: within a few months the dress was discussed in several international newspapers, on television shows and on many of the leading tech news websites such as Wired, USA Today, Gizmodo and Techcrunch. ${ }^{2}$ The concept of solar fashion was met with enthusiasm. Wired concluded that the 'Solar Dress' was the first application of solar technology '[y] ou might actually want to wear' (Stinson 2014), while a CNN Wire article was headed 'Forget smart watches: Solar dresses are the future' (O'Brien 2014) and an article on Ecouterre headlined 'Solar power goes couture with Pauline van Dongen's avant-garde wearables' (Chua 2013). In 2014, media attention continued when the dress made it into the finals of the 'South by Southwest Accelerator Awards', and when the Barbican acquired the dress for the exhibition Digital Revolution. Despite its instant success, opinions were divided when it came to the look and feel of the design. While Wired found the dress 'surprisingly wearable' (Stinson 2014), The Arts Desk commented that it looks 'like something out of Star Trek' (Kent 2014). The media attention shows some of the issues at hand: the enthusiasm for the potential applications and fashionable look of wearable technology, versus hesitations about its feasibility, wearability and futuristic aesthetics.

To provide insight into the development of solar fashion, we discuss the design process and properties of the 'Solar Dress' in more detail. The 'Solar

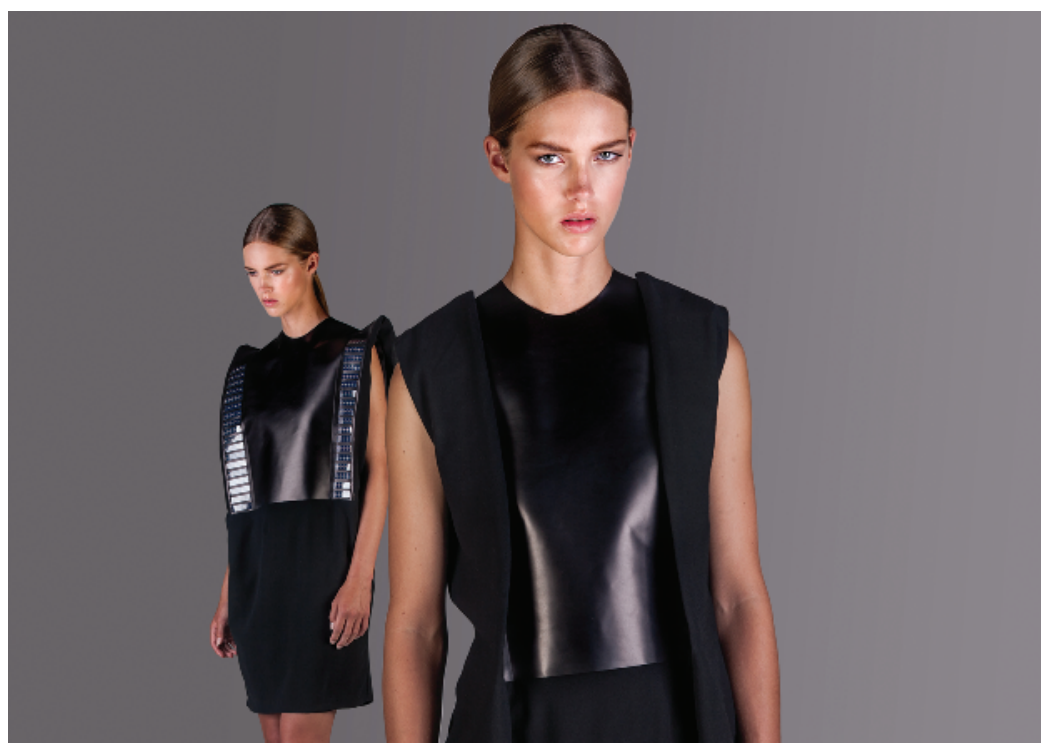

Figure 1: Pauline van Dongen, 'Wearable Solar Dress', 2013. Photograph by Mike Nicolaassen. 
Dress' contains a mix of soft and hard textiles, combining a lightweight wool fabric with crisp leather in which 72 flexible thin-film solar cells have been integrated. The solar cells allow the wearer to generate renewable energy, which can be used to charge a mobile device via a USB connector hidden inside the dress's pocket. When worn in direct sunlight for two hours the dress generates enough power to fully charge an empty battery of a typical smartphone. The stiffness of the leather does not only hold the square-cut shape of the dress, but also protects the thin solar cells from getting damaged by folding. The choice of leather is partly practical because the seams of the incisions could be left raw edge, while it creates a distinct look conveying a feeling of power further enhanced by the 'coolness' of the technology of the solar cells. Because of the dark colour of the cells, van Dongen chose to complement the design with black materials, to keep the overall look clean, minimal and fashionable. She wanted to design a dress that shows the lightness of the cells and enhances the soft side of technology creating a feminine look.

During the initial design phase for the 'Solar Dress' Pauline van Dongen explored the use of off-the-shelf solar cells that had not been developed specifically for textiles or clothing. When looking at the way these solar cells are built, she noticed how their layered construction is similar to the stratification of the human skin, which also naturally interacts with the sun. Inspired by this analogy between solar cells and human skin, she developed a layered design that contains areas with solar cells that can be opened up and revealed to the sun, thus giving the wearer control over the additional functionalities as well as the more expressive side of the dress. This modular system allows the wearer to choose to make the technology more or less visible, by folding the solar cells open or keeping them closed.

The thin-film solar cells are flexible in the sense that they can be bended and curved, but not folded firmly. Van Dongen worked with many small separate cells instead of a larger architecture of cells, to be able to position them more freely and to allow for more movement in between the separate cells. Having a large panel would make the design too rigid in one specific place and would make it look almost like a screen or a window. The fact that all the cells needed to be wired individually, inspired van Dongen to place them in vertical array in close proximity to each other. By placing the solar cells in such a linear grid, their interconnection remained short and the inside of the dress did not become a clutter of wires. Such a clutter would have increased the chance of breaking the connections through stress inflicted on the wires by body movement. The linear formation fitted well with the modular aspect that allowed the user to open up the compartments containing the solar cells. The area with the cells had to be folded on the vertical line running next to the cells, which were placed horizontally above each other. This aspect of the design process exemplifies how a functional decision can complement and enhance an aesthetic feature, and the other way around; the expressive features actually enabled and complemented the functionality of the wearable 'Solar Dress'.

The design process was inspired by the functional and material limitations that the technology imposed. The challenge was to cope with the rectangular shape of the cells and use the minimum amount needed to generate enough energy. The ideal placement of the cells was on the upper part of the body, in areas that are most exposed to the sun and relatively immobile. Because of the wiring, the efficiency of one cell can affect another, so the cells needed to be distributed quite evenly. Eventually the 72 cells were placed in two rows 
on both the front and back of the upper body. Small incisions were handcut into leather, to create pocket slits that would hold the cells in place. All the cells were first connected to each other in pairs, creating a series circuit, which were then inserted into the slits. While already being embedded in the leather, the rest of the electrical connections, namely the parallel circuitry, had to be soldered. In making the dress, the designer had to move between techniques of garment construction and electrical engineering, which made the process quite laborious. The time-consuming construction of the dress prevents it from being manufactured on a larger scale, so it remains a couturelike design.

When working with technology or a material that has a certain meaning beyond its exterior look and feel, there is an even greater need to design through, with and on the body (Tomico and Wilde 2015). In order for the interaction with sunlight to be meaningful for the wearer, enough solar cells need to be used to achieve a minimum amount of power and efficiency. In this case, meaning will thus not so much originate from the representation of an idea or concept developed by the designer, but will rather emerge from the interaction between the designer and the materials (i.e. integrating the solar cells into the design) as well as between the design and its wearer (i.e. wearing the design in a way that allows for the cells to harvest enough solar energy). Since interaction is involved the wearer should perhaps be called a user as he or she actively uses the capabilities the garment has to offer. A meaningful interaction between garment and user can only arise from a design process that acknowledges such embodied interactions. To further explain and underpin our argument for an embodied design approach to wearable technology, we now turn to the phenomenological approach as developed by Merleau-Ponty.

\section{A PHENOMENOLOGICAL APPROACH TO WEARABLE TECHNOLOGY: THEORY AND METHOD}

The work of phenomenologist Maurice Merleau-Ponty places emphasis on the body as our 'anchorage' in the world (2002 [1945]: 167). In his influential Phenomenology of Perception (1945), Merleau-Ponty addresses the close connection between human experience and artefacts, arguing that human beings relate to the world through objects. He writes: 'Our own body is in the world as the heart is in the organism: it keeps the visible spectacle constantly alive, it breathes life into it and sustains it inwardly, and with it forms a system' (Merleau-Ponty 2002 [1945]: 235). Through movement and embodied encounters with the world around us, we grasp space, and our position within space.

First of all, Merleau-Ponty's attention to the body as the 'heart' of our experiences inspires a theoretical focus on the role of the body in the experience of fashionable technology. Within fashion studies, Merleau-Ponty's thought has been used to address the topic of embodiment and experience. Joanne Entwistle, most notably, draws on Merleau-Ponty's idea of the body as the locus of experience to emphasize that dress is always located spatially and temporally. Phenomenology, she argues, teaches us that dress is to be understood as a situated embodied practice located in space and time (Entwistle 2015: 29). This understanding of the body as inhabiting space and time is relevant for fashionable technology, as it directs the attention to how wearables can rearrange the experience of spatiality and temporality for the 
wearer. Similarly, Llewellyn Negrin embraces Merleau-Ponty's phenomenology as a theoretical framework 'with which to address fashion not simply as an aesthetic or symbolic phenomenon but as a haptic experience' (Negrin 2016: 115). Connecting the phenomenological premise to fashion, she argues that the embodied aspect of body adornment is in fact paramount to the experience of fashion (Negrin 2016: 125). Focusing on embodiment, we suggest, thus helps to address the challenges and opportunities for making solar fashion physically wearable.

Secondly, Merleau-Ponty's phenomenology highlights how the almost continuous proximity of garments generally causes them to be incorporated into the 'original structure' of the body (2002 [1945]: 104). 'If I did not take off my clothes', he writes, 'I could never see the inside of them, and it will in fact be seen that my clothes may become appendages of my body' (104). According to Entwistle, therefore, any analysis of dress should include the body and explore the dynamic relationship between fabric and flesh (Entwistle 2002: 148). 'The materials we hang at the margins of our body', she writes, 'enjoy a close proximity to the flesh, outlining, emphasizing, obscuring or extending the body' (Entwistle 2002: 133). Also inspired by Merleau-Ponty's analysis, Llewellyn Negrin writes: ' $[w]$ hen we act in the world, we do not act just as bodies, but as clothed bodies, in which our attire becomes an integral part of our corporeal schema, influencing the ways in which we comport ourselves in space' (2016: 130, original emphasis). As we spend most of our lives clothed, and hardly ever experience or encounter the world without wearing clothes, clothing has become merged with the basic organization and experience of our body. The phenomenological reflection on clothing as an appendage of the body raises the question of whether solar fashion, too, has the potential to become an integral part of the wearer's embodied experience.

Thirdly, in terms of methodology we consider phenomenology of great value in studying wearable technology because of its preoccupation with lived experiences. Merleau-Ponty describes his philosophy as a 'return to the world of actual experience which is prior to the objective world', and considers it his task 'to rediscover phenomena, the layer of living experience through which other people and things are first given to us' (Merleau-Ponty 2002 [1945]: 66). $\mathrm{He}$ argues that the perceptions of the lived body make our thinking, knowledge, ideas and interpretations possible. In contrast to ethnographic research methods, the phenomenological approach thus relies on people's embodied experiences and subjective accounts of specific phenomena, rather than longterm participatory observations of routine practices (Jenss 2016). Inspired by this phenomenological attention to embodied experience, our research methodology included fitting sessions during which we gathered interview data on how wearers actually experience, use and evaluate van Dongen's 'Wearable Solar' designs. ${ }^{3}$ During the fitting sessions we integrated phenomenological theory and method by asking respondents about their physical and psychological experience of the designs, addressing aspects such as freedom of movement, body awareness, spatiality, and the weight and touch of the material as well as visual appearance, style, taste and economic value.

As Lucy Dunne notes, the obstacles to wearable technology are 'many and complex', not least because cultural aspects of physical comfort, identity and social acceptability are not taken into account (Dunne 2010: 42). Wearable technology is often pushed by scientists or technicians who strive after functionality, whereas fashion designers are more focused on issues of aesthetics without being trained to integrate technological components into the design
3. We did two fitting sessions for the 'Solar Dress' and the 'Solar Shirt'. The respondent of our first fitting (20 May 2015) was a student who had no previous knowledge of the garments or the designer. The respondent of our second fitting (21 May 2015) was a professional model who had modelled one of Pauline van Dongen's nontechnological designs in the past. Working with semi-structured in-depth interviews, we asked the two respondents (both female, in their early twenties) about their physical experience of the 'Solar Dress' and the 'Solar Shirt' respectively. The interviews were recorded and subsequently transcribed. 
(Dunne, Profita and Zeagler 2014: 25). In addition to being overlooked by many designers or technicians, the social and physical aspects of wearing technology are generally neglected in academic scholarship. By combining phenomenological theory and method with a phenomenological design practice, our research project addresses the largely underexposed aspect of embodied experience in relation to fashionable technology. The following paragraph will discuss the results of this approach for advancing the design of solar fashion specifically.

\section{EMBODIED EXPERIENCES}

Pauline van Dongen's 'Solar Dress' has been described as a best practice in uniting technology and fashion, turning fashion design into a sustainable tool (Garcia 2013; Cool Hunting 2015). Influenced by phenomenological theory, however, we noted that the dress is also illustrative of a common blind spot in the design and study of fashionable technology: embodied experience. As a 'proof of concept' that was initially exclusively presented on a catwalk or stage and in a museum space, the 'Solar Dress' largely remained disembodied. Although it may seem obvious that the physical body is central to the design or study of fashionable technology, we found that the physical and actual wearing experience often remains hidden from view. This is partly due to the fact that fashionable technology is 'not something that many of us have actually experienced' (Ryan 2014: 3). Like van Dongen's 'Solar Dress', fashionable technologies are mostly presented and studied within the context of fashion shows, research labs, conferences or museum exhibitions. Apart from models and a small group of early adopters, few people are therefore in a position to reflect on the physical experience of wearing wearable tech. Once we started to integrate phenomenological theory and methodology into our research, this supported the hypothesis that actual wearer experiences could advance the development of solar fashion.

In the first fitting with the 'Solar Dress', the respondent mentioned that she would not wear the garment on a day-to-day basis because it felt 'like a harness', was heavy and limited her freedom of movement. The same respondent expressed that she could hear and feel the technology, especially the wire coming out of the side of the dress, which made her feel she had to be careful not to break or damage the technology. Our second respondent referred to the 'stiffness' of the technology on the chest and shoulders, which to her felt as 'a kind of protection'. Both respondents also noted that the fit of the dress was uncomfortable and restraining, particularly around the neck, due to the stiff leather and narrow opening. The responses of the wearers demonstrate that the touch, shape, weight, pressure and even sound of a garment not only determine sensorial and haptic perception, but also inform bodily positioning and overall demeanour. Although the 'Solar Dress' had proven to be wearable enough for the catwalk, the wearing experiences of our respondents made clear that the technology-infused areas of the design were not yet comfortable and easy to wear in a day-to-day context, in spite of van Dongen's effort to make the dress both wearable and feminine. Attention to the embodied experience of the dress in relation to the wearers' overall evaluation of the design thus indicates that the already intimate relation between clothes and the body becomes even more salient with the advent of fashionable technology.

Another valuable result of our theoretical and methodological attention to embodied experience is that it showed how van Dongen's 'Solar Dress' 
influences the wearer's behaviour and the way she positions herself in space. One respondent noted how the 'fragility of the technology' influenced an action such as taking a seat or getting dressed. The respondents were careful not to damage the 'Solar Dress' by leaning against the back of a chair or overstretching the circuitry. Asking them questions about these embodied experiences we learned that, in the particular case of 'Solar Dress', fashionable technology restrains and emphasizes the way the wearer uses her body and relates to the physical space around her. Notwithstanding the way it physically restrains the wearer's actions and movements, it became clear that the 'Solar Dress' can, to a certain extent, become an appendage of the wearer's body. In contrast to feelings of being 'locked up' and restricted by the torso of the garment, one respondent mentioned that the unfolding shoulder pads of the dress also had an empowering effect. Connecting the wider span of her body and broadened shoulders to her psychological experience, she noted: 'I do have the idea that I look stronger when I wear it [...] but at the same time it does not feel more protective'. This also shows that the physical perceptions, sensations and interactions necessarily involved in wearing, rather than just carrying or using, technology are crucial to making solar fashion more physically wearable.

In addition to revealing how the 'Solar Dress' influences the bodily spatiality and the physical comfort of wearers, the results of the fitting sessions show that fashionable technology, like clothing in general, has the exceptional power to 'rewrite the body [and] give it a different shape and a different expression' (Svendsen 2006 [2004]: 77). The fitting sessions with van Dongen's 'Solar Dress' indicate that the new shapes and expressions of integrated technology must be carefully considered in tandem with factors such as bodily awareness, comfort and self-image. Our 'phenomenological research and design' approach has shown how fashionable technology can demarcate, empower, restrict and emphasize the wearer's body. To further explore embodied design, we now turn to our second case study: the 'Solar Shirt'.

\section{'SOLAR SHIRT'}

Pauline van Dongen defined several improvements in developing her next design in 2015, the 'Solar Shirt'. Technically, the cells needed to be wired in a less time-consuming manner and also in such a way as to closely merge the circuit with the textile. Moreover, she wanted to make the technology more adaptable to various types of garments for both genders. Finally, in terms of aesthetics, it was important to initiate a transition from an exclusive and rather futuristic-looking design towards a more accessible garment for a larger audience. From the start of 'Crafting Wearables' we believed that wearable technology can only get to the street or shops if it achieves cultural and social acceptance (Smelik 2016). It is important to create designs that are aesthetically pleasing as well as comfortable to wear, allowing the wearer to connect to fashionable technology on an intimate and personal level. In order to be wearable in an everyday context, van Dongen decided that the design of the 'Solar Shirt' needed to look less unusual and feel more socially and physically comfortable.

For the 'Solar Shirt', Pauline van Dongen used printed electronics. This involves the use of conductive inks, such as silver paste, to print circuits and electronic devices onto various thin and flexible substrates, such as plastic foils. The process is similar to familiar printing methods like offset, inkjet or screen printing. It is a relatively low-cost production method, which allows 


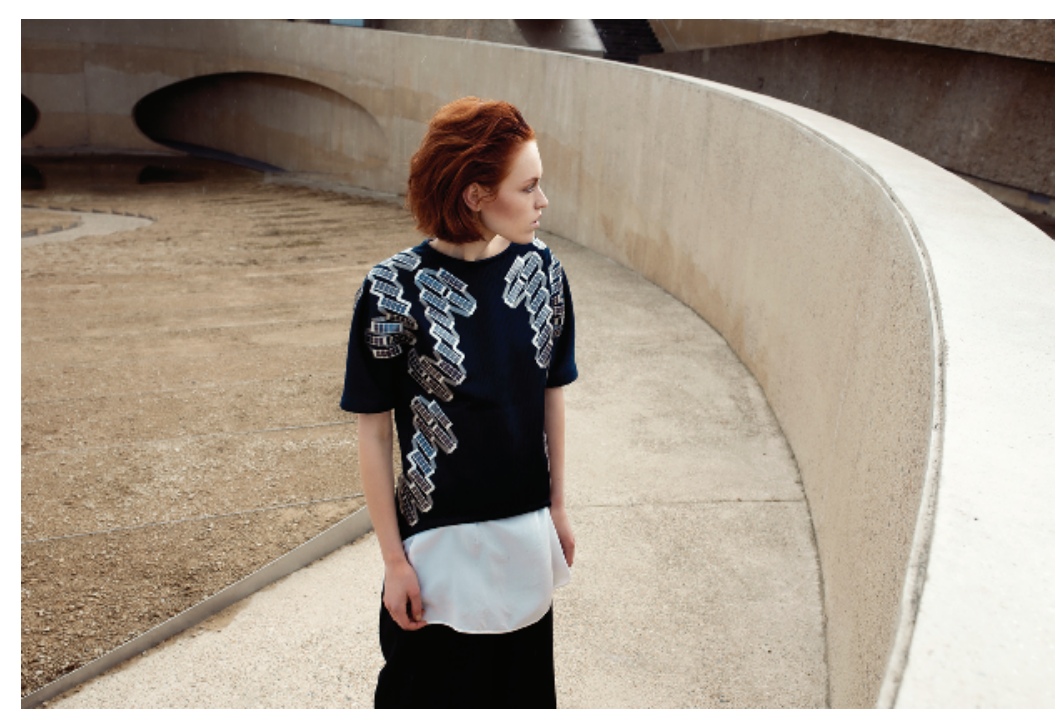

Figure 2: Pauline van Dongen, 'Solar Shirt', 2015. Photograph by Liselotte Fleur.

for quick scaling thanks to its roll-to-roll-based production. It can nevertheless be expensive to design and develop something as specific as a solar cell module. Furthermore, there are not many companies or research centres that have successfully experimented with combining printed electronics with textiles. At the time of working on the 'Solar Dress', van Dongen did not yet know the possibilities of printed electronics for textiles, but after showcasing the dress she got in touch with the R\&D Holst Centre in Eindhoven where she could make herself familiar with the technology and the opportunities it had to offer.

The use of printed electronics allowed a freer and more playful approach to the design. Unlike the linear grid of the 'Solar Dress', the cells could now be placed in various formations, although there is still the limitation of size as the electronics are printed on A4-sized sheets. The fact that van Dongen could only shape the circuitry in certain ways, turned the technology into a design element. Using the circuit as an aesthetic feature, she developed it like a graphic print. The circuit is no longer hidden on the inside (like in the dress), but is now exposed, forming an aesthetic feature thanks to its given graphic design. Seen from a distance the solar cell modules look like a print, while a close look reveals the silver-coloured meandering 'wires', which look like fine embroidery but are in fact the printed lines interconnecting the cells.

As with the design of the 'Solar Dress', the solar cell modules here too dictated the choice of fabric on which they were to be laminated. The stretch of the fabric has to match the stretch of the electronics: if there is no correct match, too much tensile force could cause the electronics to break. Compared to the dress, the 'Solar Shirt' is softer, making it more comfortable to wear. The jersey fabric provides comfort and invites the user to move freely. Yet, there were other challenges to the designs. Integrating a solar charging module, which is a rechargeable battery that can continuously store the generated energy, adds a lot of weight and thickness to the design. It was therefore quite 


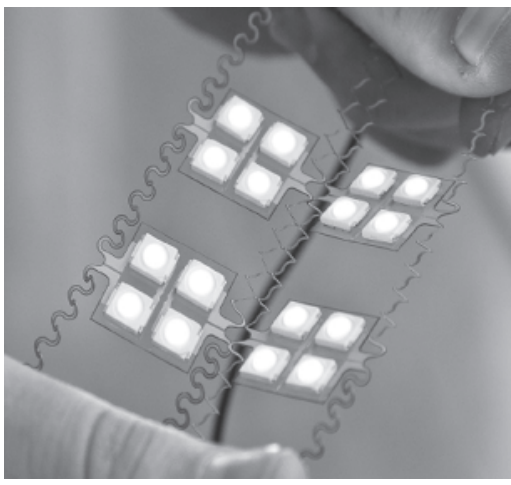

Figure 3: Sample of printed electronics with LEDs. Photograph by Holst Centre.

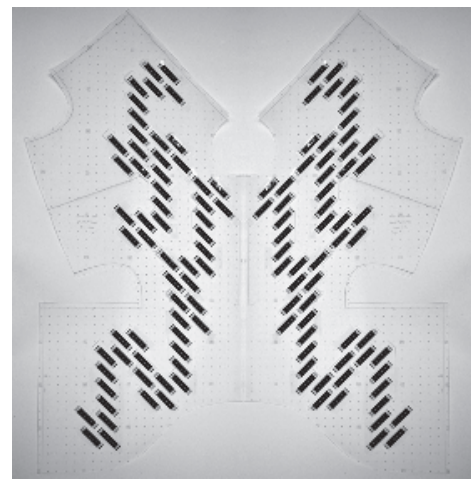

Figure 4: 'Solar Shirt' pattern consisting of one large piece. Photograph by Pauline van Dongen.

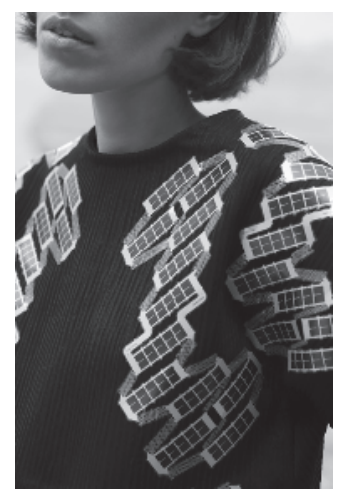

Figure 5: Detail of 'Solar Shirt', 2015. Photograph by Liselotte Fleur.

difficult to make both the dress and the shirt lightweight and not too warm to wear in the sun.

Working with a lamination process of solar cell modules created certain limitations with respect to the pattern, because it needed to consist of only one piece. Twelve cells are combined with the printed circuitry to form one A4 module, and ten of such solar cell modules need to be laminated onto the fabric of the $t$-shirt, demanding for the full $t$-shirt to be laid out flat underneath the heat press machine. In other words, the shape as a whole had to be laid flat when the modules were applied to the textile with heat and pressure. A regular t-shirt consists of four parts (front and back panel and two sleeves) that cannot be laid out flat after being sewn together. This limitation inspired van Dongen to design a structure that was built up of only one large pattern piece. Yet, even without any solar cells the t-shirt still offers a distinct shape and silhouette. In transforming a functional requirement into an aesthetic opportunity, she integrated the functionality of the technology with the aesthetics of the design. As the 'Solar Shirt' is soft, light and comfortable, the t-shirt can be situated in-between casual clothing and high fashion.

\section{EMBODIED DESIGN: AN EXPERIENTIAL APPROACH TO THE 'SOLAR SHIRT'}

So far we have shown that the very materiality of wearable technology is prominent for the actual design; for example, in the fact that the solar cells had to be paired and placed in a linear circuit; could not be sewed, stitched or folded; and had to be soldered. Moreover, the design had to become 'embodied' because wearable technology, by definition, is worn on the body (Dunne, Profita and Zeagler 2014: 25). To state the obvious, the technology is - or should be - 'wearable'. As our respondents made clear, the design has to be tailored to the body in order for it to be socially acceptable, useful and physically comfortable within a day-to-day context. To take this into account, Pauline van Dongen developed a 'phenomenological design approach' and worked towards 'embodied designs'. The term 'embodied design' was first introduced by Van Rompay and Hekkert (2001), who found empirical evidence for the theory 'that people understand the world largely based on 
bodily experiences' (2001: 39). They admonished that this insight does not yet illuminate 'the way a product is experienced when it is actually used' (2001: 46). A few years later they pursued the idea of embodied design by arguing that our understanding of objects is based on the interaction with the world around us (Van Rompay, Hekkert and Muller 2005: 360). The meaning and expression of designed objects are vitally informed by bodily experiences (377). Similarly, Hummels and Lévy (2013) argue for the importance of embodied experience and interaction for the practice of designers, grounding this idea within the phenomenological framework of Merleau-Ponty. According to Merleau-Ponty, embodiment involves an opening up to the world. It is in interaction with the world, with objects, that the body acquires its experiences. Meaning is created in interaction, which is why Hummels and Lévy argue for an 'aesthetics of interaction' (2013: 46; the term was introduced by Dalsgaard and Hansen 2008). Interestingly, they situate a phenomenological approach to embodied design in another concept taken from Merleau-Ponty, namely the idea that the human body is an object in the world but also forms the point of view on that world: 'I regard my body, which is my point of view upon the world, as one of the objects of that world' (2002 [1945]: 81). From that insight, Hummels and Lévy deduce that 'designing is rooted in a first-person perspective while intermittently taking a third-person perspective' (2013: 48).

As the 'Solar Shirt' was a more wearable piece of clothing, much less stiff and heavy than the 'Solar Dress', and also less alien or futuristic looking, we chose to not only research the third-person perspective through interviews with wearers, but to combine it with a first-person perspective. Pauline van Dongen decided to wear the shirt during various events and presentations, such as 'South by Southwest' (Austin, 2015), 'InDeSem' (Delft, 2015) and 'Bright Night' (Eindhoven, 2015), always combining the design with items of her own wardrobe to integrate it in everyday life. Pauline's first-person experience at the beginning of this article showed to us the importance for the designer to pay attention to the embodied experience of the design and to the interaction of the wearer with the environment.

The interviews with the respondents who tried on the 'Solar Shirt' yielded additional information. One of the respondents immediately exclaimed that she could still feel the battery in the pocket at the front of the shirt, but that the garment felt more 'wearable' to her than the 'Solar Dress': 'I don't hear it anymore, it feels less stiff and more flexible. This is something that fits me much better, that I would wear sooner'. To her own surprise, she was willing to wear solar fashion, whereas she had been quite negative about the function and look while fitting the 'Solar Dress': 'though the technology is still quite visible, I think that in this case it is part of the entire look of the garment'. She remarked that the 'Solar Shirt', unlike the dress, can be combined with 'something that would neutralize it a little'.

Tomico and Wilde argue that

Framing the design process by means of material explorations on the body brings awareness to the personal intricacies that are necessary to move from designing an object to be used, to an object to be worn. The body necessarily becomes part of the emerging design.

(Tomico and Wilde 2015: 1183)

Taking this into account, we found that wearable technology has a rather autonomous function stretching beyond the control of the wearer, in this case 
by accumulating the light that is touching the surface of the solar cells. As long as there is light, the solar cells remain active and energy can be stored. As van Dongen experienced herself, the 'Solar Shirt' made her particularly aware of her urban surroundings and guided her choice whether or not to move into the sunlight or stay in the shade. The wearer is thus invited to become more conscious of the environment. Moreover, from both first-hand experience and third-hand perspective we learned that the 'Solar Shirt' not only interacts with its wearer, but also simultaneously interacts with its surroundings because of its shiny cells. The technology expresses a certain look and visibility that calls for social interaction even if the wearer does not feel like it.

By deliberately bringing a first-person perspective into the design process, and evaluating the experience from a phenomenological perspective, we have further developed the process of embodied design. The 'research through design' approach, with its focus on the body, made us realize that aesthetics is not merely a question of beauty, but is highly dependent on the social and cultural context. This is how we have come to understand Hummels and Lévy's phrase 'aesthetics of interaction' (2013: 46). Our 'research through design' approach thus revealed that aesthetics is not merely superficial, but deeply embedded in functionality, bodily experience and social and cultural values. Finally, the focus on bodily experience emphasized the social and cultural value of the technology involved. Wearable technology has a physical, mental as well as social facet, as Dunne, Profita and Zeagler observe (2014: 42). The sustained focus on embodiment helped us realize that, in addition to 'doing good', solar fashion also has to 'feel good' in terms of physical comfort, aesthetics and social interaction.

\section{CONCLUSION}

The items in Pauline van Dongen's 'Wearable Solar' collection originate from ongoing research. In our interdisciplinary research project, we have tested and evaluated the 'Solar Dress' and the 'Solar Shirt' in terms of aesthetics; the robust integration of the technology; and the embodied experience of the wearer, through a mixed-method approach of research through design; interviews with wearers during fittings; and theoretical reflection. In order to better design and understand the material and embodied properties of wearable technology, we proposed a theoretical and methodological 'embodied' approach, taking our cues from phenomenology.

In evaluating the design, we learned that technology, in this case solar technology, directs the design process in new ways and commands decisions during all stages and on all levels of the development. The results of our research suggest, firstly, the importance of integrating and balancing the aesthetic and functional features of the design. In our evaluation of the design, we found that a deeply material understanding of the way in which solar technology works functionally, but also aesthetically, helps to achieve a balanced combination of technical functionality, wearability and aesthetic appeal. Such balanced integration ascertains that fashionable technology is 'pulled' by fashion rather than 'pushed' by technology.

Secondly, we found that it is paramount to design with and on the body when working with materials that have agency beyond their mere look and feel. We are thus strengthened in our view that it is necessary for the design process of robust and fashionable wearables to take into account the body of the wearer. We have taken on the peculiar blind spot of embodied experience 
in the design and study of fashionable technology. Although it may seem obvious to put the physical body centre stage, we found that the actual wearing experience often remains underexposed. Yet, a sustained focus on the body is key in understanding the interplay between interactive materials, the aesthetic design and the physical body. Interaction is the keyword here, because fashionable technology involves a reiterative process of action, reaction or interaction. In this context, we advanced the suggestion to approach the wearer as a user. The respondents from fitting sessions reveal their embodied experiences of van Dongen's designs. Their responses demonstrate that the touch, shape, weight, pressure and sound of a garment regulate sensorial and haptic perception, influencing the body's behaviour in time and space. The wearers' overall rather negative evaluation of the designs indicates that the fleshy body comes to the fore when technology is integrated into clothing and fashion. We thus learned that the design has to be tailored to the body if it wants to become socially acceptable and physically comfortable within everyday life.

Thirdly, we found that wearable technology has an independent function beyond the control of the wearer. The activity of the solar cells in response to the light makes the wearer more aware of the environment, such as the sun or shade in urban surroundings. At the same time, the shiny cells express a look that invites social interaction. Fashionable technology thus underscores that clothes - like the body itself - are a highly social phenomenon.

In wrapping up the interplay between practice and theory, we argue that a theoretical and methodological focus on materiality allows for a sustained analysis of embodiment and embodied experience, while also enabling attention to the materiality of the textile and the technology involved. In the course of our research, we have therefore extended our phenomenological approach to embodied design. The phenomenological research and embodied design approach has shown how fashionable technology can demarcate and restrict but also empower and enhance the wearer's body and experience. The 'research through design' approach contributed to the production of knowledge, as it helped us to make every part of the designing process concrete; reflect on the quality of the design; and appreciate the process of meaning making for the potential wearers. We learned to incorporate the embodied experience of the wearer into our design practice, research methods and theoretical analysis of fashionable technology. Working through our phenomenologically driven research through design, we hope to have cracked the particularly 'tough shell' of integrating solar technology into fashion so as to make solar fashion more wearable in the near future.

\section{REFERENCES}

Barrett, E. and Bolt, B. (eds) (2012), Carnal Knowledge: Towards a 'New Materialism' through the Arts, London: I.B. Tauris.

Bennett, T. and Joyce, P. (eds) (2010), Material Powers: Cultural Studies, History and the Material Turn, London and New York: Routledge.

Braddock, S. E. and O'Mahony, M. (1999), Techno Textiles: Revolutionary Textiles for Fashion and Design, London: Thames and Hudson.

— (2005), Techno Textiles 2: Revolutionary Textiles for Fashion and Design, London: Thames and Hudson.

Cadena, R. (2010), Automated Lighting: The Art and Science of Moving Light in Theatre, Live Performance, and Entertainment, 2nd ed., Burlington, MA: Focal Press. 
Chua, J. (2013), 'Solar power goes couture with Pauline van Dongen's avantgarde wearables', Ecouterre, 27 June, http://goo.gl/xmpKK0. Accessed 5 February 2015.

Cool Hunting (2015), 'CH25: Pauline van Dongen: The Dutch designer blazing the wearable technology path', Cool Hunting, 14 July, http://goo.gl/ eI2IGe. Accessed 19 February 2016.

Coole, D. and Frost, S. (eds) (2010), New Materialisms: Ontology, Agency, and Politics, Durham: Duke University Press.

Dalsgaard, P. and Hansen, L. K. (2008), 'Performing perception: Staging aesthetics of interaction', ACM Transactions of Computer-Human Interaction, 15: 3, doi: 10.1145/1453152.1453156.

Dourish, P. (2004), Where the Action Is: The Foundations of Embodied Interaction, Cambridge, MA and London: MIT Press.

Dunne, L. (2010), 'Smart clothing in practice: Key design barriers to commercialization', Fashion Practice, 2: 1, pp. 41-65.

Dunne, L., Profita, H. and Zeagler, C. (2014), 'Social aspects of wearability and interaction', in E. Sazonov and M. R. Neuman (eds), Wearable Sensors: Fundamentals, Implementation and Application, San Diego, CA: Academic Press, pp. 25-43.

Entwistle, J. (2002), 'The dressed body', in M. Evans and E. Lee (eds), Real Bodies: A Sociological Introduction, Houndmills, Basingstoke and New York: Palgrave, pp. 133-50.

— (2015), The Fashioned Body: Fashion, Dress, and Modern Social Theory, 2nd ed., Cambridge: Polity Press.

Frayling, C. (1993), 'Research in art and design', Royal College of Art Papers 1, pp. 1-5, http://goo.gl/DIHwdq. Accessed 13 June 2016.

Garcia, L. G. (2013), 'Scientific fashion: The way forward!', The Fashion Globe, http://goo.gl/FRFwN9. Accessed 19 February 2016.

Hummels, C. and Lévy, P. (2013), 'Matter of transformation', Interactions, 20: 6, pp. $42-49$.

Jenss, H. (2016), 'Exploring fashion practices through ethnography: Introduction' in H. Jenss (ed.), Fashion Studies: Research Methods, Sites, and Practices, London and New York: Bloomsbury, pp. 61-65.

Kent, S. (2014), 'Digital revolution, The Curve, Barbican: A trip for techies down Memory Lane, plus a glimpse at the "interactive" future", The Arts Desk, 4 July, http://goo.gl/MOCR9M. Accessed 5 February 2015.

Koskinen, I., Zimmerman, J., Binder, T., Redström, J. and Wensveen, S. (2011), Design Research through Practice: From the Lab, Field, and Showroom, Waltham, MA: Morgan Kaufmann.

Löwgren, J. (2013), 'Annotated portfolios and other forms of intermediatelevel knowledge', Interactions, 20: 1, pp. 30-34.

Merleau-Ponty, M. (2002 [1945]), Phenomenology of Perception (trans. D. A. Landes), London and New York: Routledge [original edition: Phénoménologie de la perception, Paris: Gallimard].

Min, G. (2009), 'Power supply sources for smart textiles', in J. McCann and D. Bryson (eds), Smart Clothes and Wearable Technology, Oxford, Cambridge and New Delhi: Woodhead Publishing, pp. 214-31.

Negrin, L. (2016), 'Maurice Merleau-Ponty: The corporeal experience of fashion', in A. Rocamora and A. Smelik (eds), Thinking through Fashion: A Guide to Key Theoristis, London: I.B. Tauris, pp. 115-31.

O'Brien, S. (2014), 'Forget smart watches: Solar dresses are the future', CNNMoney, 8 September, http://goo.gl/GwxojC. Accessed 5 February 2015. 
Quinn, B. (2002), Techno-fashion, Oxford: Berg.

- (2012), Fashion Futures, London: Merrell.

Rocamora, A. and Smelik, A. (2016), 'Introduction', in A. Rocamora and A. Smelik (eds), Thinking through Fashion: A Guide to Key Theorists, London: I.B. Tauris: pp. 1-27.

Ryan, S. E. (2014), Garments of Paradise: Wearable Discourse in the Digital Age, Cambridge, MA: MIT press.

Seymour, S. (2009), Fashionable Technology: The Intersection of Design, Fashion, Science and Technology, Vienna: Springer.

(2010), Functional Aesthetics: Visions in Fashionable Technology, Vienna: Springer.

Smelik, A. (2016) 'Cybercouture: The fashionable technology of Pauline van Dongen, Iris van Herpen and Bart Hess', in A. Smelik (ed.), Delft Blue to Denim Blue: Contemporary Dutch Fashion, London: I.B. Tauris, pp. 252-69.

Stinson, L. (2014), 'Charge your phone in style with this solar-powered dress', Wired.com, 5 May, http://goo.gl/nwTVYt. Accessed 5 February 2015.

Svendsen, L. (2006 [2004]), Fashion: A Philosophy (trans. J. Irons), London: Reaktion Books [original edition: Mote: Et Filosofisk Essay, Oslo: Universitetsforlaget].

Tomico, O. and Wilde, D. (2015), 'Soft, embodied, situated \& connected', in MobileHCI, Proceedings of the 17th International Conference on HumanComputer Interaction with Mobile Devices and Services Adjunct, Copenhagen, Denmark, 24-27 August, pp. 1179-86.

Van Rompay, T. and Hekkert, P. (2001), 'Embodied design: On the role of bodily experiences in product design', in Proceedings of the International Conference on Affective Human Factors Design, Singapore, pp. 39-46.

Van Rompay, T., Hekkert, P. and Muller, W. (2005), 'The bodily basis of product experience', Design Studies, 26: 4, pp. 359-77.

Wilson, J. I. B. and Mather, R. R. (2015), 'Photovoltaic energy harvesting for intelligent textiles', in T. Dias (ed.), Electronic Textiles: Smart Fabrics and Wearable Technology, Sawston, CA: Woodhead Publishing, pp. 155-71.

\section{SUGGESTED CITATION}

Smelik, A., Toussaint, L. and van Dongen, P. (2016), 'Solar fashion: An embodied approach to wearable technology', International Journal of Fashion Studies, 3: 2, pp. 287-303, doi: 10.1386/infs.3.2.287_1

\section{CONTRIBUTOR DETAILS}

Anneke Smelik is Katrien van Munster Professor of Visual Culture at the Radboud University Nijmegen, where she is coordinator of the Creative Industries MA programme. Her research focuses on fashion and wearable technology, especially on performance and identity from the perspective of new materialism and Deleuzean thought. She (co-)edited many books, most recently Delft Blue to Denim Blue: Contemporary Dutch Fashion (I.B. Tauris, 2016); Materializing Memory in Art and Popular Culture (Routledge, forthcoming); and Thinking Through Fashion: A Guide to Key Theorists (I.B. Tauris, 2016). She has published widely on issues of identity, body, memory and technology in cinema, videoclips, digital art and fashion. Anneke Smelik is project leader of the research programme 'Crafting Wearables; Fashionable Technology' (2013-18), funded by the Netherlands Organization for Scientific Research. See: www.annekesmelik.nl. 
Contact: Radboud University Nijmegen, Department of Cultural Studies, P.O. Box 9103, 6500 HD Nijmegen, the Netherlands.

E-mail: a.smelik@let.ru.nl

Lianne Toussaint is a Ph.D. candidate at the Department of Cultural Studies of the Radboud University Nijmegen. The central aim of her dissertation is to critically and theoretically reflect on the sociocultural dimensions of wearable (and in particular 'fashionable') technologies, focusing on their embodied, material, communicative and ethical dimensions. In 2015 she received a Fulbright Grant for a visiting scholarship at Parsons The New School for Design in New York. Toussaint holds an MA in Cultural Studies as well as an MA in Photographic Studies. Her research is part of 'Crafting Wearables; Fashionable Technology' (2013-18), a collaborative research project funded by the Netherlands Organization for Scientific Research. See: www.craftingwearables.com.

Contact: Radboud University Nijmegen, Department of Cultural Studies, P.O. Box 9103, 6500 HD Nijmegen, the Netherlands.

E-mail: 1.toussaint@let.ru.nl

Pauline van Dongen is a fashion designer who graduated with a Master's degree from the ArtEZ Academy of Fashion in Arnhem (the Netherlands). Next to her fashion design studio in Arnhem she is also a Ph.D. candidate at the Department of Industrial Design of the Technical University Eindhoven. In her dissertation, and designs, she aims to address the creative and aesthetic aspects of the design process of wearable technology in order to create a desirable integration of technology and fashion using scalable solutions. Her design research is part of 'Crafting Wearables; Fashionable Technology' (2013-18), a collaborative research project funded by the Netherlands Organization for Scientific Research. See: www.paulinevandongen.nl.

E-mail: contact@paulinevandongen.nl

Anneke Smelik, Lianne Toussaint and Pauline van Dongen have asserted their right under the Copyright, Designs and Patents Act, 1988, to be identified as the authors of this work in the format that was submitted to Intellect Ltd. 
